\title{
Arsenic (V) removal from aqueous system using adsorbent developed from a high iron-containing fly ash
}

\author{
Yi Li, Fu-Shen Zhang *, Fu-Rong Xiu \\ Research Center for Eco-Environmental Sciences, Chinese Academy of Sciences, 18 Shuangqing Road, Beijing 100085, China
}

\section{A R T I C L E I N F O}

\section{Article history:}

Received 16 February 2009

Received in revised form 6 July 2009

Accepted 10 July 2009

Available online 3 August 2009

\section{Keywords:}

Arsenate

Fly ash

Loading mechanism

Ferric oxide

\begin{abstract}
A B S T R A C T
A novel adsorbent for arsenic $(\mathrm{V})$ removal from wastewater was developed through simple chemical processes using a special iron-abundant fly ash. In the synthesis process, the inherent iron in the fly ash was rearranged and loaded on the surface of the fly ash by dissolution and precipitation processes. The adsorbent (HIOFAA) was characterized by XRD, FT-IR, SEM, LPS and BET surface area. The results showed that porous amorphous FeOOH was loaded on the surface of HIOFAA successfully. The BET surface area of HIOFAA was 22 times of those of the original fly ash, and furthermore, the mean particle size of HIOFAA increased 3 times compared to the raw fly ash, thus effectively accelerated the solid/liquid separation after the adsorptive treatment. The adsorption isotherm data could be well described by Langmuir isotherm model, and the adsorption capacity for arsenic removal was $19.46 \mathrm{mg} \mathrm{g}^{-1}$. Accordingly, it is believed that the adsorbent developed in this study is effective for arsenic polluted wastewater treatment.
\end{abstract}

(c) 2009 Elsevier B.V. All rights reserved.

\section{Introduction}

Arsenism has become one of the most serious endemic diseases in China in the last decade due to arsenic pollution. It was reported that over 2 million people are exposing to arsenic polluted water and about 10,000 persons were diagnosed as arsenism patients (Sun, 2004; Kanel et al., 2005). Elevated arsenic concentrations in groundwater are mainly caused by human activities and natural processes, e.g., mining, release of industrial wastewater and disposal of chemical wastes. In recent years, economic development in China has led to the annual increase of quantity of discharged wastewater containing high arsenic concentration. Currently, a variety of treatment methods have been intensively researched for arsenic removal from contaminated water. The major methods involve adsorption, ion exchange, nanofiltration, reverse osmosis, electrodialysis, precipitation-coagulation, oxidation-precipitation, and biological treatment (Zhang and Itoh, 2005; Baciocchi et al., 2005; Han et al., 2002; Kang et al., 2000; Weng et al., 2005; Meng et al., 2002; Zhang and Itoh, 2006; Katsoyiannis et al., 2002). Among them, adsorption using a variety of ironcontaining materials has been proven to be economical, effective and easy for operation. Thus several iron-containing materials, such as amorphous hydrous iron oxide $(\mathrm{FeOOH})$, goethite $(\alpha-\mathrm{FeOOH})$ and akaganeite $(\beta-\mathrm{FeOOH})$ (Raven et al., 1998; Lakshmipathiraj et al., 2006; Solozhenkin et al., 2003), have been examined and proven to be promising adsorptive materials due to their removing efficiency.

\footnotetext{
* Corresponding author. Tel./fax: +8610 62849515.

E-mail address: fszhang@rcees.ac.cn (F.-S. Zhang).
}

Among these materials, amorphous hydrous iron oxide has the highest adsorption capability since it has the highest surface area. However, this iron-containing adsorbent is merely available as fine powders or exists as gel or suspension in aqueous solution, hence it is difficult to separate entirely from the treated solution after the adsorption reactivity. In order to overcome this shortage, some matrices were selected to support or load those iron oxides. The matrices include municipal solid waste (MSW), cement, sand, activated alumina (AA), silica oxide and alginate beads (Zhang and Itoh, 2005; Kundu and Gupta, 2002; Hsua et al., 2008; Guo et al., 2007; Vaishya and Gupta, 2002; Kuriakose et al., 2004; Zeng, 2003; Zouboulis and Katsoyiannis, 2002). Previous studies showed that these synthetic Fe-loaded adsorbents had good affinities and high removal efficiency for arsenic.

In a previous study, we successfully loaded amorphous FeOOH on the surface of municipal solid waste melted slag through chemical reactions and high temperature coating treatments (Zhang and Itoh, 2005). Moreover, Fan et al. (2008) have synthesized another ironimpregnated adsorbent for arsenic removal using the MSW and coal co-combustion ash. Among the foregoing studies, chemical agents, such as $\mathrm{FeCl}_{3}, \mathrm{FeSO}_{4}$, were necessary for the adsorbents synthesis. Thus high iron-containing waste materials are desirable for the production of the adsorbents since they can avoid adding the iron source in the process of synthesis. Recently, we have found a new type of coal fly ash with iron oxide as high as $17.52 \%$. This type of ash is an ideal Fe-containing raw material for the synthesis of adsorbent for arsenic removal.

The aim of this study was to develop a new route for effective utilization of the special type of fly ash. A novel adsorbent, containing high amount of amorphous $\mathrm{FeOOH}$ on the surface of fly ash, was 
synthesized using simple chemical reactions. The adsorbent was applied for arsenic removal from aqueous system, and the optimum conditions were established.

\section{Experimental}

\subsection{Materials}

Fly ash was sampled from Gaobeidian thermal power plant $(4 \times 200 \mathrm{MW})$ located in Beijing (China). The ash was verified to be safe for the environment and has realized the commercial utilization in the traditional areas such as concrete, pavement and dam. The ash was collected by an electrostatic precipitator after the pulverized coal burnt in the cyclone furnace boiler. After sampling, part of the ash was dried at $105^{\circ} \mathrm{C}$ for $24 \mathrm{~h}$ and stored in a desiccator for use. Typical chemical composition of the ash is listed in Table 1.

Stock solution containing $1000 \mathrm{mg} \mathrm{l}^{-1}$ of arsenic (V) was prepared from analytical pure $\mathrm{Na}_{3} \mathrm{AsO}_{4} \cdot 12 \mathrm{H}_{2} \mathrm{O}$ following the procedure: Firstly, $\mathrm{Na}_{3} \mathrm{AsO}_{4} \cdot 12 \mathrm{H}_{2} \mathrm{O}$ was directly dissolved into a $10 \mathrm{ml}$ of distilled water, then transferred to a 1-1 volumetric flask and diluted to a predetermined volume. Arsenic working solutions were freshly made by diluting stock solution with distilled water. $\mathrm{HCl}(1 \mathrm{M}, 0.1 \mathrm{M}), \mathrm{HNO}_{3}$ $(1 \mathrm{M}, 0.1 \mathrm{M})$ and $\mathrm{NaOH}(1 \mathrm{M}, 0.1 \mathrm{M})$ solutions were prepared for $\mathrm{pH}$ adjustment.

\subsection{Adsorbent synthesis}

According to Fan et al. (2005), some alkali and alkaline earth elements, such as $\mathrm{K}_{2} \mathrm{O}, \mathrm{Na}_{2} \mathrm{O}, \mathrm{CaO}$ and $\mathrm{MgO}$, were removed from the raw ash by washing the sample with hot water so as to reduce the consumption of hydrochloric acid in the process of adsorbent synthesis.

The high iron oxide fly ash adsorbent (HIOFAA) was prepared according to the following procedure: Firstly, $3.0 \mathrm{~g}$ of raw fly ash was added to $250 \mathrm{ml}$ of water, and the mixture was stirred and heated to $95^{\circ} \mathrm{C}$ for $1 \mathrm{~h}$, then the insoluble part in the mixture was filtrated and rinsed repeatedly until the $\mathrm{pH}$ of leachate remained 6.0-7.0. The insoluble material obtained was dried at $100{ }^{\circ} \mathrm{C}$ for $2 \mathrm{~h}$. Secondly, the pretreated fly ash was contacted with $100 \mathrm{ml}$ of $1 \mathrm{M} \mathrm{HCl}$ solution, vibrated for $2 \mathrm{~h}$ and placed steadily at $60^{\circ} \mathrm{C}$ for $0.5 \mathrm{~h}$. The color of the solution gradually changed to yellow from transparency. Thirdly, $1 \mathrm{M}$ $\mathrm{NaOH}$ solution was added dropwise into the solution until the final $\mathrm{pH}$ was adjusted to about 6.0, and the orange gel appeared in the solution. The mixture continuously was vibrated for $1 \mathrm{~h}$, and then aged at $75^{\circ} \mathrm{C}$ for 3 days. Finally, the slurry was dewatered by centrifugation and continuously rinsed for several times with distilled water $(100 \mathrm{ml}$ of water was used per washing cycle) until the $\mathrm{pH}$ of the leachate remained constant in three consecutive rinses, then dried at $75{ }^{\circ} \mathrm{C}$ for $24 \mathrm{~h}$. Upon cooling, $3.43 \mathrm{~g}$ of composite solid was obtained. The solid was broken to separate the powders in the carnelian mortar, and afterwards stored in the capped polyethylene bottle for use.

\subsection{Analysis}

In order to discuss the loading mechanisms of HIOFAA, raw fly ash (RFA), acidized fly ash (AFA) and the final product HIOFAA were examined, among which, AFA was obtained by the following procedure: after the raw fly ash was acidized adequately at $60{ }^{\circ} \mathrm{C}$ for $0.5 \mathrm{~h}$ by $\mathrm{HCl}$ solution (above mentioned), the remnant insoluble part was separated from the mixture by centrifugation, then washed for

Table 1

Chemical composition of the fly ash employed in this study.

\begin{tabular}{llllllllll}
\hline Properties & $\mathrm{LOI}$ & $\mathrm{SiO}_{2}$ & $\mathrm{Al}_{2} \mathrm{O}_{3}$ & $\mathrm{Fe}_{2} \mathrm{O}_{3}$ & $\mathrm{CaO}$ & $\mathrm{MgO}$ & $\mathrm{SO}_{3}$ & $\mathrm{~K}_{2} \mathrm{O}$ & $\mathrm{Na}_{2} \mathrm{O}$ \\
\hline
\end{tabular}

\begin{tabular}{llllllllll}
\hline Percentage (Mass, \%) & 0.27 & 29.33 & 25.70 & 17.52 & 22.17 & 1.60 & 4.15 & 0.56 & 1.81
\end{tabular}

three times with distilled water, and finally dried at $75^{\circ} \mathrm{C}$ for $24 \mathrm{~h}$. The final solid power obtained was identified as acidized fly ash (AFA).

The X-ray diffraction (XRD) patterns of RFA, AFA and HIOFAA were obtained using X-ray diffractometer (Philips PW 1700, Holland). The operating conditions were $45 \mathrm{kV}$ and $250 \mathrm{~mA}$, using $\mathrm{Cu} \mathrm{K} \alpha$ radioactive source. The samples were scanned in the range of $10^{\circ}$ to $60^{\circ}$, and JCPDS (Joint Committee on Powder Diffraction Standards) files were used for the identification of crystalline compounds. The surface morphology of RFA, AFA and HIOFAA were obtained using scanning electron micrograph (SEM) (Hitachi S-3000 N, Japan). The functional groups of RFA, AFA and HIOFAA were tested by the technology of Fourier transform infrared spectrometry (FT-IR) (Nicolet Nexus670, USA) in the wavenumbers of $4000-400 \mathrm{~cm}^{-1}$. The technology of laser particle size (LPS) was used to analyze the particle size distribution of the three samples by the laser particle sizer (Master size 2000, Malvern Co, UK). The BET (Brunauer-Emmet-Teller) specific surface area was determined by fitting the linear portion of the BET plot to BET equation, and pore size distribution was calculated based on the desorption plot of $\mathrm{N}_{2}$ adsorption-desorption isotherm using the Barrett-Joyner-Halenda (BJH) method (Micrometritics ASAP 2000, USA). Skeleton density and porosity of HIOFAA and AFA were measured based on the water displacement method proposed in Black. Meanwhile, porosity was calculated using the equation (Lin and $\mathrm{Wu}, 2001$ )

$\varepsilon_{P}=1-\frac{\rho_{S}}{\rho_{p}}$

where $\varepsilon_{p}$ is the porosity of adsorbent, $\rho_{s}$ is the skeleton density of adsorbent $\left(\mathrm{g} \mathrm{cm}^{-3}\right)$ and $\rho_{s}$ is the density of AFA $\left(\mathrm{g} \mathrm{cm}^{-3}\right)$.

After the adsorptive reaction, the supernatants were collected and arsenic concentration was examined by inductively coupled plasma optical emission spectrometer (ICP-OES) (PerkinElmer OPTIMA 2000, USA).

\subsection{Batch experiment}

In order to optimize arsenic removal conditions, the effects of aging time, solution $\mathrm{pH}$, arsenic initial concentration, contact time and HIOFAA dosage on arsenic removal were comprehensively tested. Specifically, a series of 50-ml capped polyethylene bottle were shaken in a shaker at room temperature (nearly $25^{\circ} \mathrm{C}$ ) and $220 \mathrm{rpm}$. In each test, $25 \mathrm{ml}$ of arsenic solution was loaded in the bottle. Arsenic concentrations were in the range of 1.0 to $100 \mathrm{mg} \mathrm{l}^{-1}$ and HIOFAA dosage was in range of 2.0 to $60 \mathrm{~g}^{-1}$. The $\mathrm{pH}$ (from 1.5 to 13 ) value was adjusted to the desired level with $\mathrm{HNO}_{3}$ or $\mathrm{NaOH}$ solution. During the adsorption process, the test bottles were shaken for a fixed time (from 2.0 to $30 \mathrm{~h}$ ), then the suspensions were immediately centrifuged to separate the solid from the solution. The supernatant were sampled and then analyzed by ICP-MS for the equilibrium arsenic concentration. Arsenic removal was calculated by the difference between the concentrations of arsenic before and after adsorption. Arsenic concentrations in unit of $\mathrm{mg}^{-1}$, are all given as elemental arsenic.

\section{Results and discussion}

\subsection{Characterization of the adsorbents}

The X-ray diffraction (XRD) patterns of RFA, AFA, and HIOFAA are showed in Fig. 1. The main diffraction peaks of RFA are assigned to quartz $\left(\mathrm{SiO}_{2}\right)$, hematite $\left(\mathrm{Fe}_{2} \mathrm{O}_{3}\right)$, Anhydrite $\left(\mathrm{CaSO}_{4}\right)$, Magnetite $\left(\mathrm{Fe}_{3} \mathrm{O}_{4}\right)$ and lime $(\mathrm{CaO})$. However, different from previous report (Jing et al., 2008), aluminium mineralogical phrases, such as mullite, could not be found although the composition of $\mathrm{Al}_{2} \mathrm{O}_{3}$ in the raw fly ash is as high as $25.70 \%$ (Table 1 ). In the XRD pattern of AFA, the quartz 


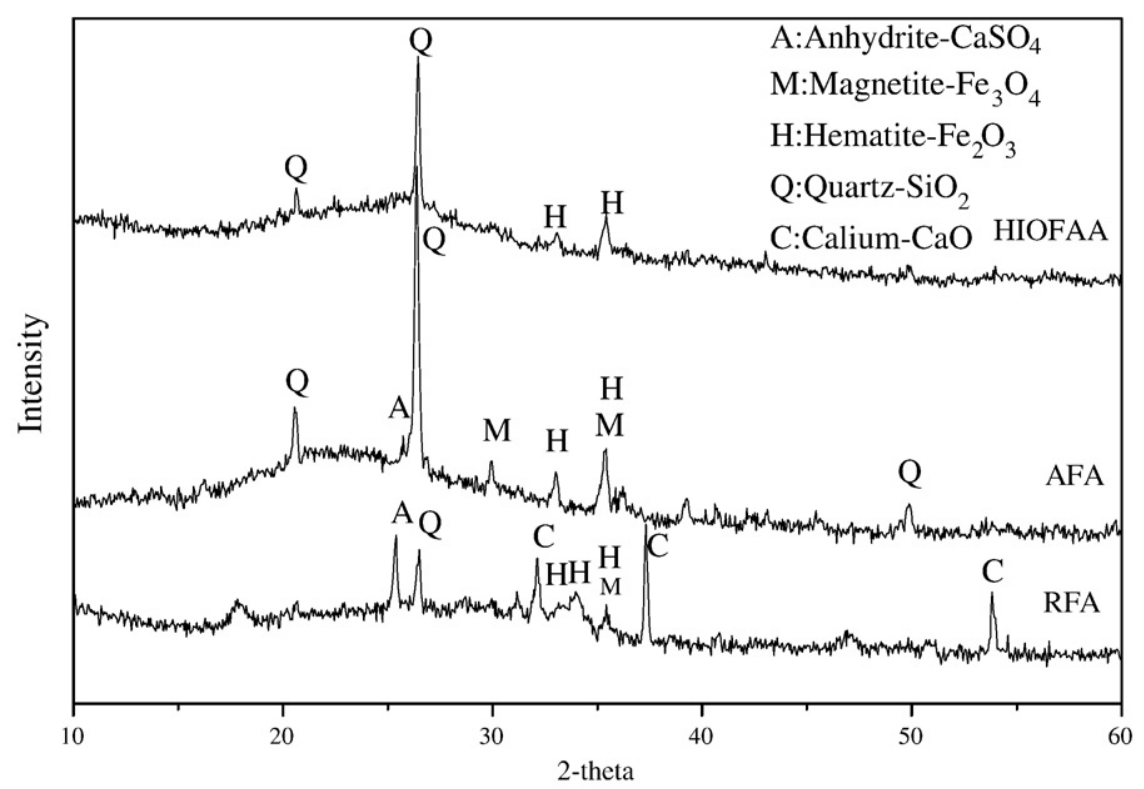

Fig. 1. X-ray diffraction patterns of RFA, AFA and HIOFAA.

becomes the main crystalline phase and minor hematite, magnetite and Anhydrite is still existed. This shows that the content of quartz increases and the mineral containing elemental Fe (hematite and magnetite) decreases after the process of acidic treatment. In the XRD pattern of HIOFAA, no new diffraction peaks appear and no new crystalline phase is observed in contrast with AFA, and moreover, the diffraction peaks of magnetite disappear, indicating that the loaded new substance in the surface of the HIOFAA is amorphous. Meanwhile, the magnetite on the surface of AFA is covered up and hereby XRD diffraction peaks vanish entirely.

Fig. 2 illustrates the FT-IR transmittance spectra of RFA, AFA and HIOFAA. In contrast with RFA, the adsorption at $1103 \mathrm{~cm}^{-1}$ assigned to the vibration of $\mathrm{Fe}-\mathrm{O}$ bond (Fan et al., 2008), and the band at $997 \mathrm{~cm}^{-1}$ assigned to the asymmetric stretching vibration of T-O ( $\mathrm{T}=\mathrm{Si}, \mathrm{Al}$ ) bonds (El-Naggar et al., 2008), faint dramatically, showing that a great portion of iron oxide and aluminium oxide dissolved into the $\mathrm{HCl}$ solution, but the typical bands $\left(1084,785\right.$ and $\left.461 \mathrm{~cm}^{-1}\right)$ of quartz (Fernández-Jiménez and Palomo, 2005), become more obvious, which could attribute to the inertness of quart and thereby enrichment in the AFA. In the spectra of HIOOFA, the new bands at 3486 and $1662 \mathrm{~cm}^{-1}$ is assigned to $\mathrm{O}-\mathrm{H}$ vibration, the former corresponds to $\mathrm{O}-\mathrm{H}$ stretching vibration and the latter to deformation vibration bond (Elizalde-Gonźalez et al., 2001), implying that the new substance loaded in the HIOFAA exits in the form of hydroxy compound.

The morphology changes of RFA, AFA and HIOFAA are showed in Fig. 3. The images of HIOFAA show that the final powder is drastically different from the original ash. The surface of HIOFAA is coated entirely by the hydroxy compounds and gets into porous network structure, while the size of granule also increases sharply. LPS analysis shows that the mean particle size of RFA and HIOFAA are 5.51 and $21.05 \mu \mathrm{m}$, respectively. The final product is nearly 4 times as large as RFA, which can efficiently accelerate separation effect after adsorptive treatment. In a blank test for comparison, equivalent RFA replaced HIOFAA to remove arsenic from the solution in the same conditions. After the treatment and vibration, the solution was turbid and it took more than $2 \mathrm{~h}$ for the solution to become clear, but it took only several minutes for HIOFAA to get clear.

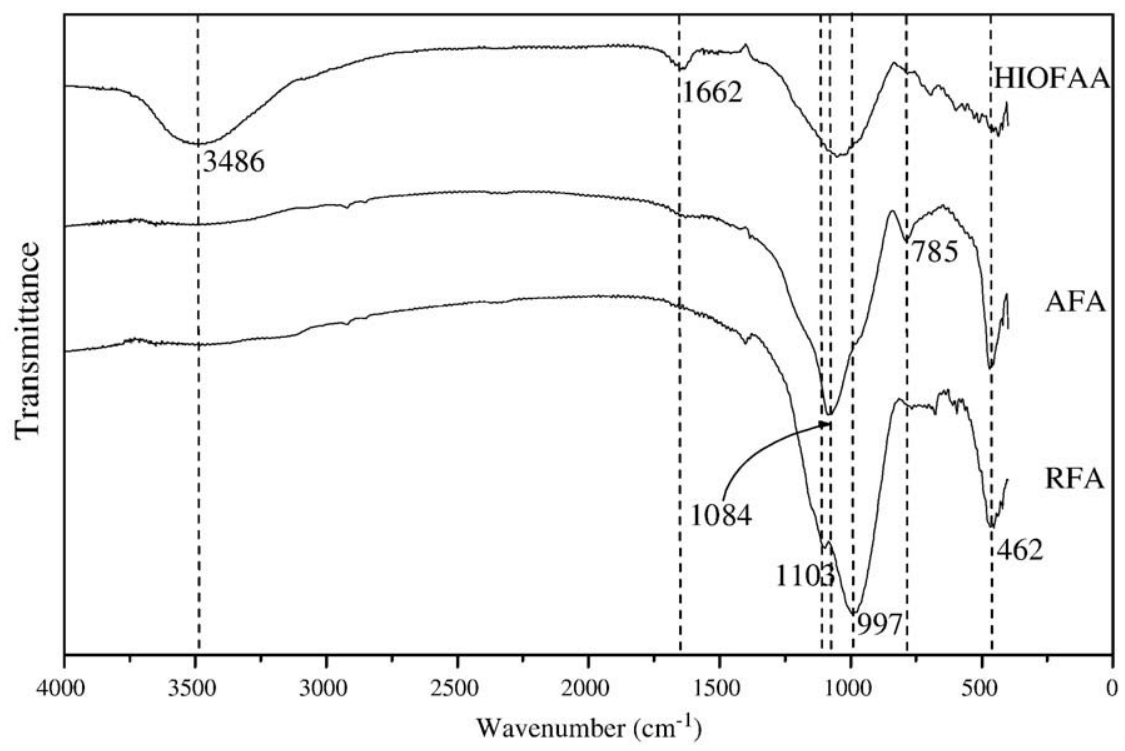

Fig. 2. FT-IR spectra of RFA, AFA and HIOFAA. 


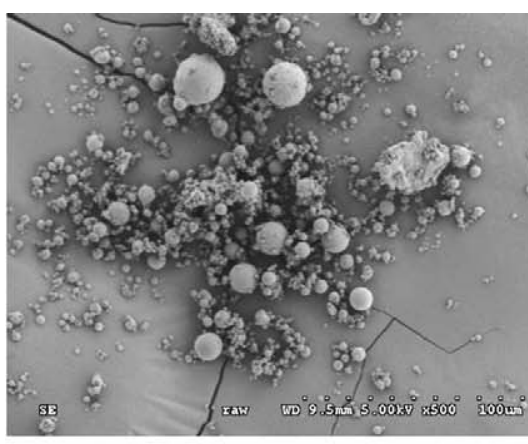

RFA

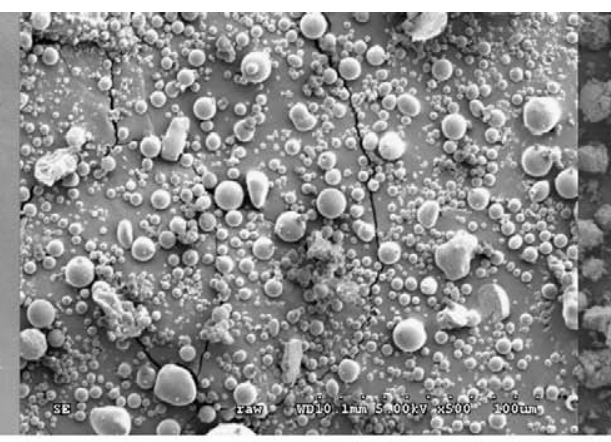

AFA

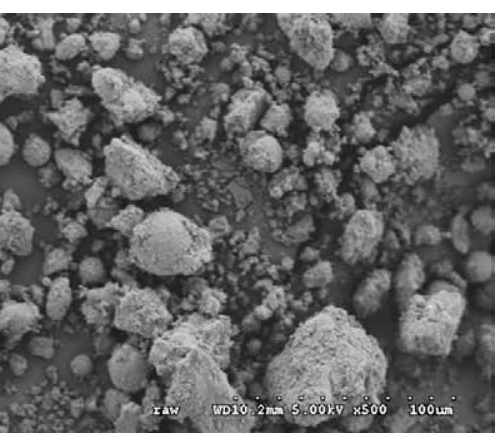

HIOFAA

Fig. 3. SEM images of RFA, AFA and HIOFAA.

The nitrogen adsorption-desorption isotherm of HIOFAA with the pore size distribution is shown in Fig. 4. The Type IV adsorption isotherm of HIOFAA and its hysteresis loop imply the mesoporous structure of material. The pore size distribution confirms that the pore size of HIOFAA ranged from $21 \AA$ to $505 \AA$, the average pore size was $23 \AA$, and porosity was $17.8 \%$.

\subsection{Loading mechanisms}

Fly ash is rich in aluminum and iron oxides, and is thought to be very important source of pre-mined material, hence many researchers have studied the ash leachability under the acidic conditions for the extraction of alumina, iron, and the other heavy metal elements (Matjie et al., 2005; Baba and Kaya, 2004; Sočo and Kalembkiewicz, 2007). When fly ash contacts with hydrochloric acid, most of the metals, such as $\mathrm{Fe}$ and $\mathrm{Al}$, can leach into the solution through the following reactions:

$$
\begin{aligned}
& \mathrm{Fe}_{2} \mathrm{O}_{3} \text { (amorphous, crystalline) }+6 \mathrm{H}^{+} \rightarrow \mathrm{Fe}^{3+}+3 \mathrm{H}_{2} \mathrm{O} \\
& \mathrm{Fe}_{3} \mathrm{O}_{4} \text { (crystalline) }+8 \mathrm{H}^{+} \rightarrow \mathrm{Fe}^{2+}+2 \mathrm{Fe}^{3+}+4 \mathrm{H}_{2} \mathrm{O} \\
& \mathrm{Al}_{2} \mathrm{O}_{3} \text { (amorphous) }+6 \mathrm{H}^{+} \rightarrow 2 \mathrm{Al}^{3+}+3 \mathrm{H}_{2} \mathrm{O} .
\end{aligned}
$$

During the reaction, the color of mixture in the conical flask gradually changed to light yellow due to the dissolution of $\mathrm{Fe}^{3+}$ in the fly ash. When the slurry was adjusted with sodium hydroxide solution to raise its alkalinity, $\mathrm{Fe}^{2+}, \mathrm{Fe}^{3+}$ and $\mathrm{Al}^{3+}$ precipitated through the

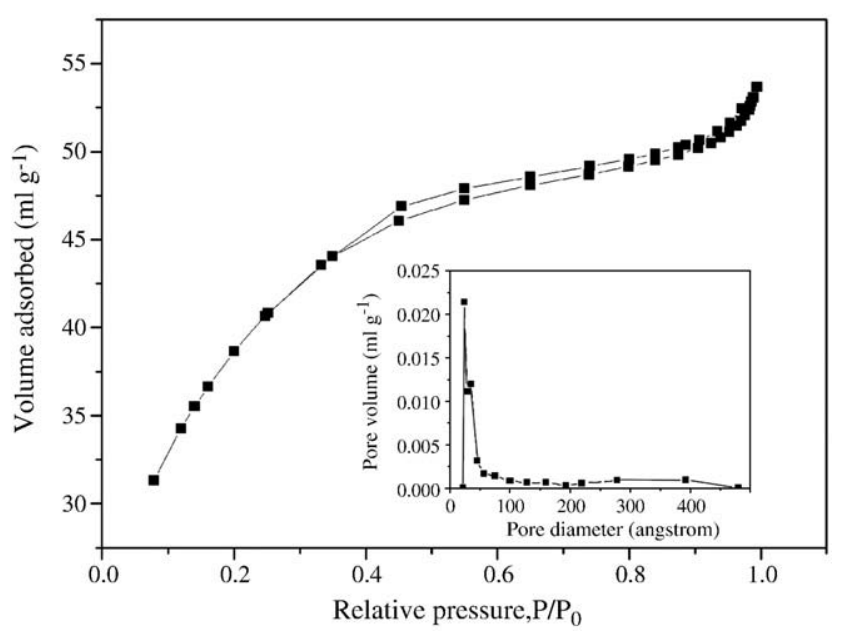

Fig. 4. Nitrogen adsorption-desorption isotherm and pore size distribution of HIOFAA. following reactions, the slurry of mixture became orange from light yellow, indicating that Fe ion was precipitated from the solution.

$\mathrm{Fe}^{2+}+2 \mathrm{OH}^{-} \rightarrow \mathrm{Fe}(\mathrm{OH})_{2} \downarrow$

$4 \mathrm{Fe}(\mathrm{OH})_{2}+\mathrm{O}_{2}+2 \mathrm{H}_{2} \mathrm{O} \rightarrow 4 \mathrm{FeOOH} \downarrow+4 \mathrm{H}_{2} \mathrm{O}$

$\mathrm{Fe}^{3+}+3 \mathrm{OH}^{-} \rightarrow \mathrm{FeOOH} \downarrow+\mathrm{H}_{2} \mathrm{O}$

$\mathrm{Al}^{3+}+3 \mathrm{OH}^{-} \rightarrow \mathrm{Al}(\mathrm{OH})_{3} \downarrow$.

Literature shows that $\mathrm{Fe}$ and $\mathrm{Al}$ ions precipitate from aqueous solution when $\mathrm{pH}$ value of solution is adjusted to 3.0 and 3.5, respectively (Matjie et al., 2005). In our experiments, the precipitation of white $\mathrm{Fe}(\mathrm{OH})_{2}$ was firstly observed in the solution, but it changed into orange simultaneously, indicating that $\mathrm{Fe}(\mathrm{OH})_{2}$ was oxidized to $\mathrm{Fe}(\mathrm{OH})_{3}$.

When fly ash contacts with acidic solution, the bonds of $\mathrm{Si}-\mathrm{O}$ on the surface of spherical glassy particle increase due to dissolution of the other metal elements. Moreover, when $\mathrm{FeOOH}$ precipitate from the aqueous solution and coated on the surface of residual fly ash, $\mathrm{Fe}-\mathrm{Si}$ surface complex (typically, $\mathrm{Fe}-\mathrm{O}-\mathrm{Si}(\mathrm{OH})_{3}$ ) occur between Fe and $\mathrm{Si}$ in situ as reported in the previous literature (Swedlund and Webster, 1999), hence increase the physical strength of the adsorbents (Zhang and Itoh, 2005). This has been confirmed in batch arsenic removal experiments, where no disintegration of the adsorbents happened after the treatment. It was also testified in the filtration experiment that the HIOFAA adsorbent was easily filtered with a clean filtrate with a filter paper (Grade 42, Whatman) which particle retention size was $2.5 \mu \mathrm{m}$. In contrast, a significant portion of particles passed though the similar filter paper during filtration of laboratory-made pure $\mathrm{FeOOH}$ suspension (Zeng, 2003). This observation indicated that no $\mathrm{FeOOH}$ suspension was disintegrated from the adsorbent.

Furthermore, silica on the surface of the particle could block or retard the transformation of initially formed $\mathrm{FeOOH}$ to crystalline iron oxides such as ferrihydrite, goethite and hematite. Arsenic adsorbent, the crystalline form of $\mathrm{FeOOH}$, e.g. goethite and ferrihydrite, is not desired, since it has much less surface area than its amorphous form, and will reduce arsenic removal capability (Zhang and Itoh, 2005). In sum, the high arsenic removal capability of HIOFAA was attained in this system, and the high physical strength of adsorbent was also formed during the chemical process.

\subsection{Effect of contact $\mathrm{pH}$}

The effect of solution $\mathrm{pH}$ on arsenic (V) removal by HIOFAA was studied in an initial pH range of 1.5 to 13.0. Fig. 5 shows that arsenic (V) was effectively removed in the initial $\mathrm{pH}$ range of 1.0 to 8.0, especially a removal peak around the $\mathrm{pH}$ of 2.5 appeared, with arsenic removal amount of as high as $23.0 \mathrm{~g} \mathrm{~kg}^{-1}$. Therefore, HIFAA was 
effective over a wider range of $\mathrm{pH}$ than the other adsorbents prepared by addition of extra iron source. For example, the adsorbents of IOLMS (Zhang and Itoh, 2005) which was synthesized by adding $\mathrm{FeCl}_{3}$ solution on municipal solid waste incinerator melted slag, had the highest arsenic $(\mathrm{V})$ removal at the $\mathrm{pH}$ of 1.5 , but removal efficiency sharply decreased along with the increase of $\mathrm{pH}$ value.

The wide $\mathrm{pH}$ range for the utilization of HIOFAA could be attributed to aluminium hydroxide existed in the surface of the adsorbents, since it is effective in a wide $\mathrm{pH}$ range on arsenic removal (Mohan and Pittman, 2007). Accordingly, the removal mechanisms of HIOFAA for the arsenic include not only adsorption but also reaction with the oxide of both iron and aluminium on the surface of HIOFAA.

For comparing the removal of arsenic (V) by HIOFAA and the raw fly ash, test was conducted at $\mathrm{pH} 2.5$ under the same conditions. The values of removal by the raw ash and HIOFAA were $11.2 \mathrm{~g} \mathrm{~kg}^{-1}$ and $23.0 \mathrm{~g} \mathrm{~kg}^{-1}$, respectively, which indicated that the HIOFAA was much effective than the raw ash and its removal capability was 2 times of raw fly ash in this condition. This phenomenon could mainly attribute to the porous structure on the surface of HIOFAA and hereby the high surface area, e.g. the BET surface area for HIOFFA and RFA were 6.23 and $140.07 \mathrm{~m}^{2} / \mathrm{g}$, respectively. Loading of hydroxy compound on the surface of the residual fly ash increased the specific surface area for nearly 22 times compared to the raw ash, thus enhanced the efficiency of adsorption greatly.

\subsection{Batch adsorption results}

In the batch experiments, high arsenic concentrations were performed since wastewaters in refining plants (e.g., gold and silver refining plants) usually contain high arsenic concentrations. To obtain the adsorption equilibrium time, kinetic adsorption experiments were conducted, in which the HIFAA dosage was $2 \mathrm{~g}^{-1}$ and the initial arsenic concentration was $50 \mathrm{mg} \mathrm{l}^{-1}$. Profile of contact time and the arsenic removal by the HIOFAA is presented in Fig. 6 (a), the results showed that arsenic removal increased sharply at the first $6 \mathrm{~h}$ and adsorption equilibrium was attained in $8 \mathrm{~h}$.

The effect of adsorbent dose on arsenic (V) removal is showed in the Fig. 6 (b), the removal efficiency of arsenic (V) increased sharply with the increase of adsorbent dose at the first stage (the dose was below $20 \mathrm{~g} \mathrm{l}^{-1}$ ). However, the removal of arsenic increased slowly when more adsorbents were added into the solution till arsenic was fully adsorbed. In China the regulated limit on arsenic disposal in industrial wastewater is $0.05 \mathrm{mg} \mathrm{l}^{-1}$. It is observed that $40 \mathrm{~g}$ of HIFAA was sufficient to remove $50 \mathrm{mg}$ Arsenic (V) from $1 \mathrm{l}$ aqueous solution to meet the standard value.

Arsenic solutions at different initial concentration from 1.0 to $100 \mathrm{mg} \mathrm{l}^{-1}$ were treated with $2.0 \mathrm{~g} \mathrm{l}^{-1}$ of adsorbent at $\mathrm{pH}$ 2.5. Fig. 6 (c)

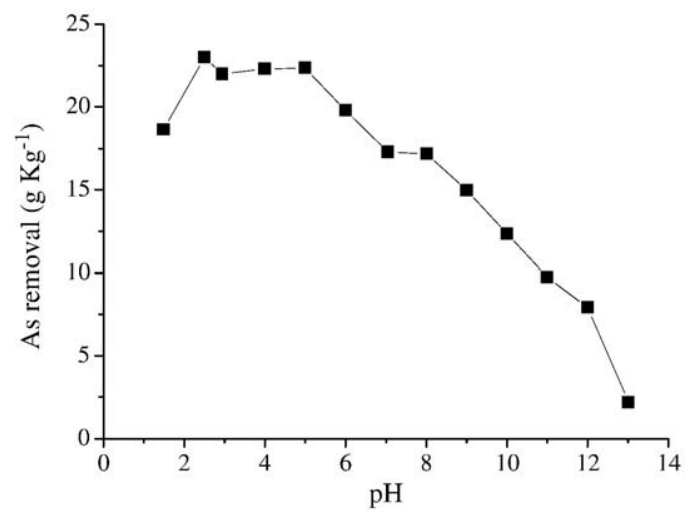

Fig. 5. Effect of $\mathrm{pH}$ on arsenic adsorption by HIOFAA. Reaction conditions: arsenic concentration $=50 \mathrm{mg} \mathrm{l}^{-1}$, adsorbent dose $=2 \mathrm{~g} \mathrm{l}^{-1}$, contact time $=15 \mathrm{~h}$.
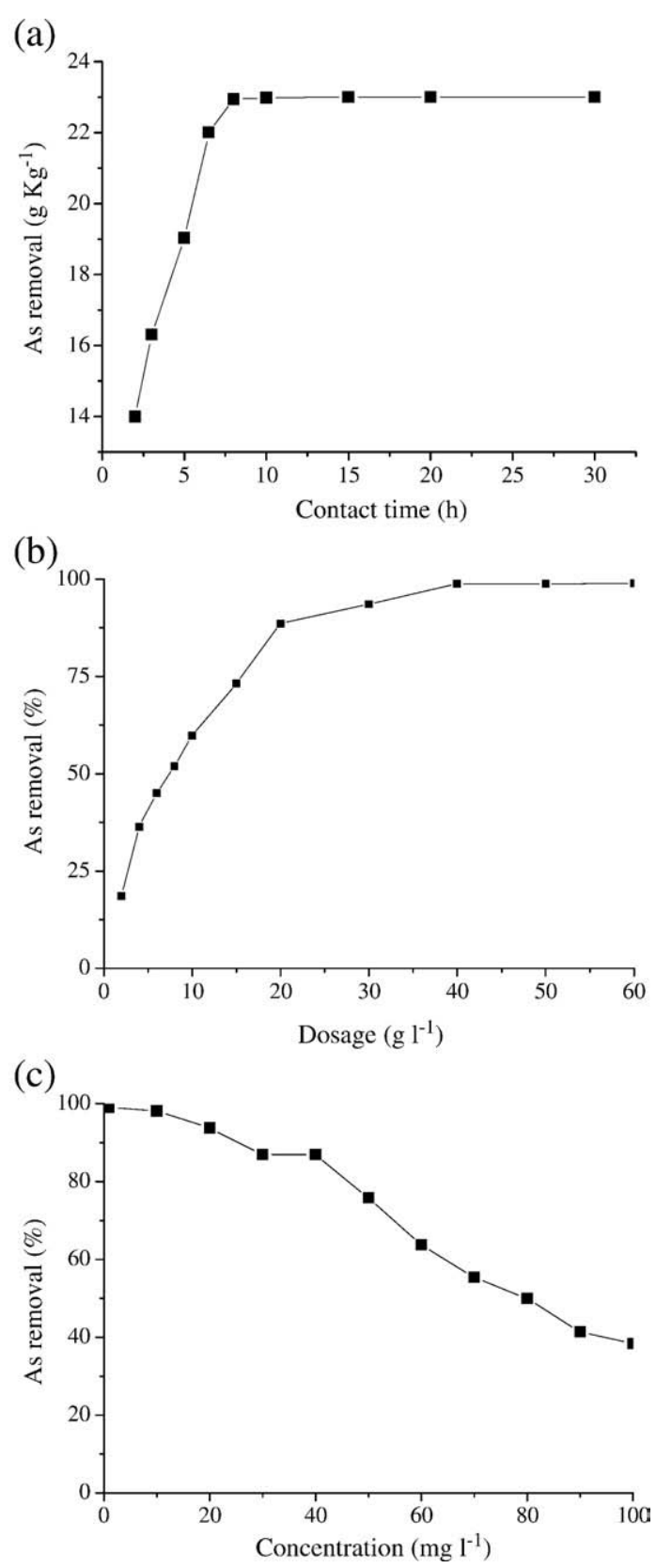

Fig. 6. Arsenic removal by HIOFAA as a function of (a) contact time, (b) HIOFAA dosage and (c) initial concentration. Reaction conditions for (a): arsenic concentration $=50 \mathrm{mg}$ $\mathrm{l}^{-1}$, adsorbent dose $=2 \mathrm{~g} \mathrm{l}^{-1}, \mathrm{pH}=2.5$; for $(\mathrm{b})$ : arsenic concentration $=50 \mathrm{mg} \mathrm{l}^{-1}$, contact $\mathrm{pH}=2.5$, contact time $=8 \mathrm{~h}$; for $(\mathrm{c})$ : dosage $=2 \mathrm{~g} \mathrm{l}^{-1}$, contact $\mathrm{pH}=2.5$, contact time $=8 \mathrm{~h}$.

shows that the effect of varying arsenic concentration against the removal efficiency of the arsenic. As expected, removal efficiency of arsenic decreased with the increasing of initial arsenic concentration, which manifested that the adsorption by the HIOFAA depended on the availability of binding sites for arsenic. When the initial arsenic concentration was $1.0 \mathrm{mg} \mathrm{l}^{-1}$, the removal efficiency of arsenic could reach above $99 \%$ and the final concentration was decreased below $0.01 \mathrm{mg} \mathrm{l}^{-1}$.

\subsection{Arsenic adsorption isotherm model}

In general, adsorption isotherm is used to describe the equilibrium state of adsorbate, adsorbent and solute at a given temperature. The 
Table 2

Langmuir and Freundlich isotherm constants.

\begin{tabular}{|c|c|c|c|c|c|}
\hline \multicolumn{3}{|c|}{ Langmuir $\left(\frac{C_{e}}{q_{e}}=\frac{1}{q_{\max } K_{l}}+\frac{C_{e}}{q_{\max }}\right)$} & \multicolumn{3}{|c|}{$\begin{array}{l}\text { Freundlich } \\
\left(\log q_{e}=\log K_{F}+\frac{1}{n} \log C_{e}\right)\end{array}$} \\
\hline $\mathrm{q}_{\max }\left(\mathrm{mg} \mathrm{g}^{-1}\right)$ & $\mathrm{K}_{\mathrm{l}}\left(\mathrm{l} \mathrm{mg}^{-1}\right)$ & $R_{\mathrm{L}}^{2}$ & $\bar{n}$ & $\mathrm{~K}_{\mathrm{F}}\left(\mathrm{mg} \mathrm{g}^{-1}\right)$ & $R_{\mathrm{F}}^{2}$ \\
\hline 19.455 & 1.41 & 0.998 & 2.61 & 0.0717 & 0.876 \\
\hline
\end{tabular}

$\mathrm{C}_{\mathrm{e}}\left(\mathrm{mg} \mathrm{l}^{-1}\right)$ : equilibrium arsenic concentration; $q_{\mathrm{e}}\left(\mathrm{mg} \mathrm{g}^{-1}\right)$ : arsenic adsorption at equilibrium concentration; $q_{\max }, K_{\mathrm{l}}, n, K_{\mathrm{F}}$ : adsorption constants.

arsenic adsorption data were analyzed with both Langmuir and Freundlich isotherm models since they are classical and simple to describe the equilibrium between metal irons onto adsorbent and metal irons in solution at a constant temperature. The respective empirical constants for the Langmuir and Freundlich isotherm models along with correlated coefficients $\left(R^{2}\right)$ were presented in Table 2 . The $R^{2}$ values obtained from the Langmuir and Freundlich isotherm were 0.998 and 0.876, respectively, indicating that the Langmuir isotherm fit better to HIOFAA than the Freundlich isotherm. Namely, the adsorption of arsenic $(\mathrm{V})$ by HIOFAA was due to monolayer coverage of arsenic $(\mathrm{V})$ onto homogeneous surface without interaction between adsorbed molecules. The Langmuir isotherm plot for the adsorption of arsenic (V) onto the HIOFAA was showed in Fig. 7, and the adsorption capacity $\left(q_{\max }\right)$ obtained from the Langmuir isotherm model (Table 2 ) was $19.46 \mathrm{mg} \mathrm{g}^{-1}$, which was much higher than that of the other adsorbents made from the ash by the way of adding iron source (e.g. $13.04 \mathrm{mg} \mathrm{g}^{-1}$ ) (Fan et al., 2008), which should be ascribed to the high BET specific surface area of HIOFAA.

\section{Conclusions}

The study provided a potential application for the fly ash, as a kind of solid waste from thermal power stations, to be reused to control water pollution. An effective adsorbent for arsenic (V) removal from aqueous system has been successfully developed using high ironcontaining fly ash as raw material. The adsorbent was in porous structure with specific surface area of $140 \mathrm{~m}^{2} / \mathrm{g}$, which was 22 times of that of the raw ash. Moreover, the particle size of HIOFAA was 4 times of the original fly ash, thus it could be easily separated from aqueous solution after arsenic adsorption process. Batch experiments showed that HIOFAA was effective for arsenic (V) removal. About $40 \mathrm{~g}$ of HIFAA was sufficient to remove $50 \mathrm{mg}$ arsenic $(\mathrm{V})$ from $1 \mathrm{l}$ aqueous solution to meet the standard value for the industrial wastewater discharge.

The HIOFAA developed in this work has the following advantages over traditional iron-oxide adsorbents for arsenic removal: (1) avoiding

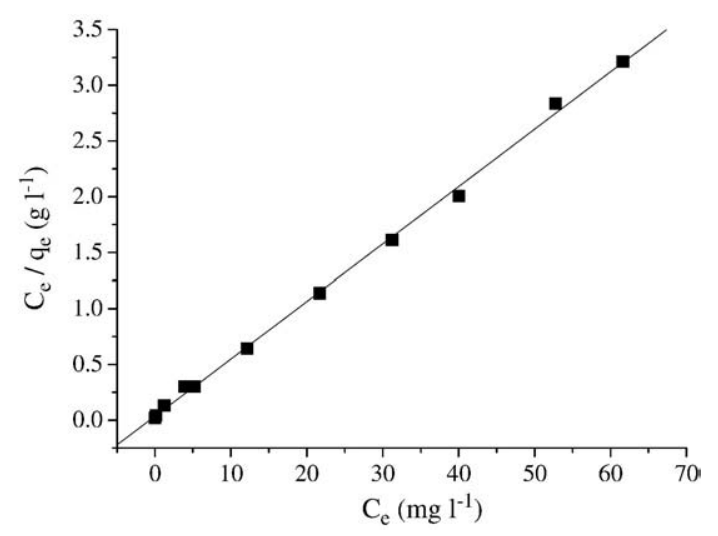

Fig. 7. Langmuir plot for the adsorption of arsenic onto the HIOFAA. the addition of the extra iron source thus reducing the cost of arsenic treatment; (2) increasing the particle size and making it easy to separate from aqueous system after adsorption activity; (3) changing the surface structure of powder particle into porous structure, thus increasing the surface area and promoting arsenic removal capacity; (4) easy for preparation since all the chemical reactions occur under mild conditions.

\section{Acknowledgements}

This work was financially supported by the National Basic Research Program of China (2007CB407303) and the National Key Technology R \& D Program (2008BAC32B03).

\section{References}

Baba A, Kaya A. Leaching characteristics of solid wastes from thermal power plants of western Turkey and comparison of toxicity methodologies. J Environ Manag 2004;73:199-207.

Baciocchi R, Chiavola A, Gavasci R. Ion exchange equilibria of arsenic in the presence of high sulphate and nitrate concentrations. Water Sci Technol: Water Supply 2005;5:67-74.

Elizalde-Gonźalez MP, Mattusch J, Wennrich R, Morgenstern P. Uptake of arsenite and arsenate by clinoptilolite-rich tuffs. Microporous Mesoporous Mater 2001;46:277-86.

El-Naggar MR, El-Kamash AM, El-Dessouky MI, Ghonaim AK. Two-step method for preparation of NaA-X zeolite blend from fly ash for removal of cesium ions. J Hazard Mater 2008;154:963-72.

Fan MH, Browna RC, Wheelock TD, Cooper AT, Nomura M, Zhuang YH. Production of a complex coagulant from fly ash. Chem Eng J 2005;106:269-77.

Fan Y, Zhang FS, Feng Y. An effective adsorbent developed from municipal solid waste and coal co-combustion ash for As (V) removal from aqueous solution. J Hazard Mater 2008;159:313-8.

Fernández-Jiménez A, Palomo A. Mid-infrared spectroscopic studies of alkali-activated fly ash structure. Micropor Mesopor Mater 2005;86:207-14.

Guo HM, Stüben D, Berner Z. Arsenic removal from water using natural iron mineralquartz sand columns. Sci Total Environ 2007;377:142-51.

Han B, Runnells T, Zimbron J, Wickramasinghe R. Arsenic removal from drinking water by flocculation and microfiltration. Desalination 2002;145:293-8.

Hsua JC, Lin CJ, Liao C, Chena ST. Removal of As (V) and As (III) by reclaimed iron-oxide coated sands. J Hazard Mater 2008;153:817-26.

Jing Z, Jin F, Hashida T. Influence of additions of coal fly ash and quartz on hydrothermal solidification of blast furnace slag. Cement Concrete Res 2008;38:976-82.

Kanel SR, Manning B, Charlet L, Choi H. Removal of arsenic (III) from groundwater by nanoscale zero-valent iron. Environ Sci Technol 2005;39:1291-8.

Kang M, Kawasaki M, Tamada S, Kamei T, Magara Y. Effect of $\mathrm{pH}$ on the removal of arsenic and antimony using reverse osmosis membranes. Desalination 2000;131:293-8.

Katsoyiannis I, Zouboulis A, Althoff H, Bartel H. As (III) removal from roundwater using fixed-bed up flowbioreactors. Chemosphere 2002;47:325-32.

Kundu S, Gupta AK. Adsorptive removal of As (III) from aqueous solution using iron oxide coated cement (IOCC): evaluation of kinetic, equilibrium and thermodynamic models. Sep Purif Technol 2002;52:165-72.

Kuriakose S, Singh TS, Pant KK. Adsorption of As (III) from aqueous solution onto iron oxide impregnated activated alumina. Water Qual Res J Can 2004;39:258-66.

Lakshmipathiraj P, Narasimhan BRV, Prabhakar S, Raju GB. Adsorption of arsenate on synthetic goethite from aqueous solutions. J Hazard Mater 2006;136:281-7.

Lin TF, Wu JK. Adsorption of arsenic and arsenate within activated alumina grains: equilibrium and kinetics. Water Res 2001;35:2049-57.

Matjie RH, Bunt JR, van Heerden JHP. Extraction of alumina from coal fly ash generated from a selected low rank bituminous South African coal. Miner Eng 2005;18:299-310.

Meng XG, Korfiatis GP, Bang S, Bang KW. Combined effects of anions on arsenic removal by iron hydroxide. Toxicol Lett 2002;133:103-11.

Mohan D, Pittman CU. Arsenic removal from water/wastewater using adsorbents-a critical review. J Hazard Mater 2007;142:1-53.

Raven KP, Jain A, Loeppert RH. Arsenite and arsenate adsorption on ferrihydrite: kinetics, equilibrium, and adsorption envelopes. Environ Sci Technol 1998;32:344-9.

Sočo E, Kalembkiewicz J. Investigations of sequential leaching behaviour of $\mathrm{Cu}$ and $\mathrm{Zn}$ from coal fly ash and their mobility in environmental conditions. J Hazard Mater 2007; $145: 482-7$.

Solozhenkin PM, Deliyanni EA, Bakoyannakis VN, Zouboulis AI, Matis KA. Removal of As (V) ions from solutions by akaganeite $\beta-\mathrm{FeO}(\mathrm{OH})$ nanocrystals. J Mining Sci 2003;39:287-96.

Sun GF. Arsenic contamination and arsenicosis in China. Toxicol Appl Pharm 2004;198: 268-71.

Swedlund PJ, Webster JG. Adsorption and polymerization of silicic acid on ferrihydrite and its effect on arsenic adsorption. Water Res 1999;33:3413-22.

Vaishya RC, Gupta SK. Modeling arsenic (V) removal from water by sulfate modified iron-oxide coated sand (SMIOCS). J Chem Technol Biotechnol 2002;78:73-80. 
Weng YH, Chaung-Hsieh LH, Lee HH, Li KC, Huang CP. Removal of arsenic and humic substances (HSs) by electro-ultrafiltration (EUF). J Hazard Mater 2005;122:171-6. Zeng L. A method for preparing silica-containing iron (III) oxide adsorbents for arsenic removal. Water Res 2003;37:4351-8.

Zhang FS, Itoh $\mathrm{H}$. Iron oxide-loaded slag for arsenic removal from aqueous system. Chemosphere 2005;60:319-25.
Zhang FS, Itoh $\mathrm{H}$. Photocatalytic oxidation and removal of arsenite from water using slag-iron oxide- $\mathrm{TiO}_{2}$ adsorbent. Chemosphere 2006;65:125-31.

Zouboulis AI, Katsoyiannis IA. Arsenic removal using iron oxide loaded alginate beads. Ind Eng Chem Res 2002;41:6149-55. 